\title{
Successful transition from pediatric to adult care in inflammatory bowel disease: what is the key?
}

\author{
Jeongseok Kim ${ }^{1}$, Byong Duk Ye $\mathrm{e}^{1,2}$ \\ ${ }^{1}$ Department of Gastroenterology and ${ }^{2}$ Inflammatory Bowel Disease Center, Asan Medical Center, University of Ulsan College of Medicine, \\ Seoul, Korea
}

The incidence of pediatric-onset inflammatory bowel disease (IBD) is on the rise, accounting for up to $25 \%$ of IBD cases. Pediatric IBD often has extensive bowel involvement with aggressive and rapidly progressing behavior compared to adult IBD. Because IBD has a high morbidity rate and can have a lifelong impact, successful transition from pediatric to adult care is important to maintain the continuity of care. Furthermore, successful transition facilitates appropriate development and psychosocial well-being among patients, as well as comprehensive and harmonious healthcare delivery amongst stakeholders. However, there are various obstacles related to patients, family, providers, and organizations that interfere with successful transition. Successful transition requires a flexible and tailored plan that is made according to the patient's developmental abilities and situation. This plan should be established through periodic interviews with the patient and family and through close collaboration with other care providers. Through a stepwise approach to the transition process, patients' knowledge and self-management skills can be improved. After preparation for the transition is completed and the obstacles are overcome, patients can be gradually moved to adult care. Finally, successful transition can increase patients' adherence to therapy, maintain the appropriate health status, improve patients' self-management, and promote self-reliance among patients. (Intest Res 2019;17:24-35)

Key Words: Transition; Inflammatory bowel disease; Crohn disease; Colitis, ulcerative

\section{INTRODUCTION}

Pediatric-onset IBD is increasing in many countries. ${ }^{1,2}$ It accounts for $15 \%$ to $25 \%$ of IBD cases, and $4 \%$ to $10 \%$ of pediatric-onset IBD cases are diagnosed in children under the age of $6 .{ }^{3}$ The annual incidence of pediatric-onset IBD has been reported to be as high as $23,15.2$, and 11.4 per 100,000 personyears in Europe, North America, and Asia, respectively. ${ }^{4}$

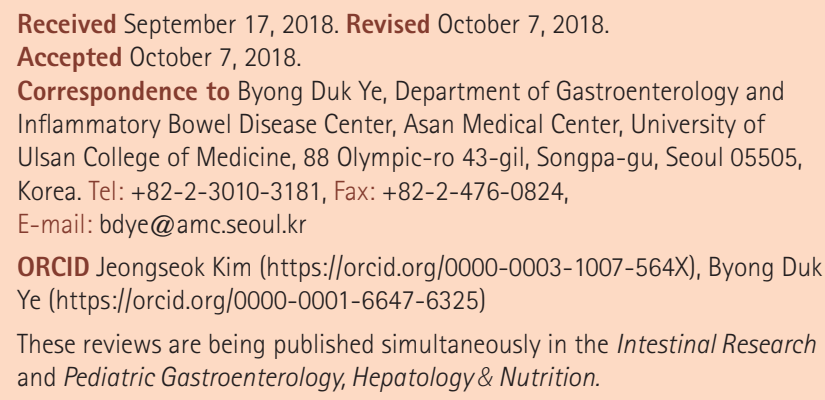

In contrast to adult-onset IBD, pediatric-onset IBD often shows extensive disease and rapid progression requiring early immunomodulatory therapy ${ }^{5,6}$ Furthermore, medical treatment as well as IBD itself can affect many aspects such as growth, education, employment, psychosocial and sexual development in pediatric patients. ${ }^{7}$ Since IBD is a lifelong disorder and disease-related morbidity can be high, a smooth and successful transition from pediatric to adult care is important.

However, several barriers have been reported that interfere with successful transition. Patients with IBD often show inadequacies in their preparation for transition, such as a lack of knowledge about the condition and its treatment and a lack of self-management skills. ${ }^{8,9}$ In a Western study, $65 \%$ of adult gastroenterologists reported that training in adolescent care was suboptimal. ${ }^{9}$ Only half of pediatric gastroenterologists reported that they are familiar with the published transition guidelines, and only $12 \%$ reported that their approach to transition 
was mostly or entirely based on the guidelines. ${ }^{10-12}$ In addition, most institutions did not have a written transition policy and lacked the resources and training for transition care. ${ }^{13}$ There was also a perception gap between pediatric and adult gastroenterologists regarding transition management and patients' competencies for successful transition. $^{9}$

Several previous reviews about transition care in IBD have extensively focused on the topics such as pediatric and adult IBD care paradigms, concepts of transition, current practice of transition care, skills needed for successful transition, evaluation of transition readiness, structured transition care program and process, barriers and outcomes of transition, and transition recommendations. ${ }^{14-18}$ In this review, we will summarize the key practical knowledge for successful transition from current literatures and actions required by pediatric and adult gastroenterologists who are preparing for transition care.

\section{EPIDEMOLOGY AND CLINICAL CHARACTERIS- TICS OF PEDIATRIC-ONSET AND ADULT-ONSET} IBD

In previous studies, the age for classifying pediatric-onset and adult-onset IBD ranged from 15 to 19 years. ${ }^{19}$ Pediatric IBD differs from adult IBD in several clinical aspects. In Western literatures, $\mathrm{CD}$ was reported to be 1.6 to 3.1 times more common than UC in pediatric-onset IBD patients, whereas CD was 0.85 times less common than UC in adult-onset IBD patients. ${ }^{6,20-22}$ In a Japanese nationwide registry, UC to CD ratio in children was 2.7, which was lower than the figure in adults (5.1). ${ }^{23}$ Although there are some differences in the incidence rates for overall IBD, the incidence of UC is slightly higher among men, while the incidence of CD is $20 \%$ to $30 \%$ higher among women in high-incidence areas, and CD occurs more frequently among men in some low-incidence areas. ${ }^{24}$ In pediatric-onset IBD groups, there is a male predominance for $\mathrm{CD}$ and no gender predilection for UC. ${ }^{23,25,26}$ Regarding familial clustering, $21 \%$ of pediatric-onset IBD patients had affected first- or second-degree relatives in a population-based study from Wisconsin. ${ }^{27} \mathrm{~A}$ family history of IBD has been also reported to be more frequent in pediatric-onset than adult-onset IBD patients according to a population-based study from northern France and a nationwide registry from Japan. ${ }^{23,28}$

In pediatric-onset CD patients on the EUROKIDS registry, the ileocolon (L3, 53\%) was the most frequently involved site at diagnosis, followed by the colon (L2, 27\%), isolated terminal ileal disease with or without limited cecal disease (L1, 16\%), and isolated upper GI tract (L4, 4\%). ${ }^{29}$ Upper GI tract involvement (L4) was reported in $54 \%$ of pediatric CD cases. ${ }^{29} \mathrm{Com}-$ pared to adult-onset $\mathrm{CD}$, pediatric-onset $\mathrm{CD}$ has a higher proportion of panenteric/extensive disease (L3+L4: 43\% vs. 3\%, $P<0.001)$ and less frequent isolated ileal (L1: $3 \%$ vs. $32 \%, P<0.001$ ) and colonic disease (L2: $15 \%$ vs. $36 \%, P<0.001$ ) at diagnosis in a Scottish patient population. ${ }^{6}$ With regard to the behavior of $\mathrm{CD}$, most patients (82\%) had inflammatory disease (B1), and $12 \%$ and $5 \%$ had structuring (B2) and penetrating disease (B3) at diagnosis, respectively. ${ }^{29}$ Perianal disease (p) was reported in $9 \%$ of pediatric-onset CD patients. ${ }^{29}$ In pediatric-onset UC patients on the EUROKIDS registry, pancolitis (E4), extensive colitis (E3), left-sided colitis (E2), and proctitis (E1) were reported in $69 \%, 9 \%, 18 \%$, and $5 \%$ of patients at diagnosis, respectively. ${ }^{30}$ Similarly, according to Asian studies, at diagnosis, ileocolonic involvement (L3) and inflammatory disease (B1) were the most common phenotype in pediatric-onset $\mathrm{CD}$, and extensive colitis (E3) was also the most common disease extent in pediatric-onset UC. ${ }^{23,31-33}$

In a French cohort study, active disease, defined as the occurrence of a flare-up or a complication during each year between 1995 and 2007, was more frequently observed in pediatric-onset than adult-onset CD patients (37\% vs. $31 \%$ of patient-years, $P<0.001$ ) between 1995 and 2007 (A total of 6,585 patient-years evaluated). ${ }^{34}$ Progression to stricturing or penetrating phenotypes (B2 or B3) from inflammatory behavior (B1) was reported in $24 \%$ to $43 \%$ and $14 \%$ to $44 \%$ of pediatriconset CD patients, respectively. ${ }^{35}$ New perianal complications developed in $10 \%$ to $20 \%$ of patients between 5 and 10 years after the diagnosis of $\mathrm{CD} .{ }^{19}$ In pediatric-onset UC patients, proximal disease extension was observed in half of the patients, and extensive colitis was observed in two-thirds of the patients at the end of various follow-up periods. ${ }^{36}$

Approximately $20 \%$ of pediatric-onset CD patients first present with short stature, predominant perianal disease, anemia, or other extraintestinal manifestations. ${ }^{37}$ Overall, a large proportion of CD patients (65\%-75\%) have been reported to be undernourished. ${ }^{38}$ Undernutrition, particularly in pediatriconset CD patients, is associated with stunting, linear growth retardation, and delayed puberty. ${ }^{39}$ The etiology of growth failure is multifactorial and includes chronic undernutrition, increased metabolic demand, cytokine-induced growth hormone resistance, and corticosteroids. ${ }^{40}$ Impairment of linear growth may be observed in up to $46 \%$ and $3 \%$ to $10 \%$ of pediatric-onset CD and UC patients at the time of diagnosis, respectively. ${ }^{41}$ According to a population-based study from France 
and a cohort study from the United States, $29 \%$ and $11.3 \%$ of pediatric-onset CD patients did not reach their target height, respectively. ${ }^{42,43}$ Since the largest increases in bone mass occurs between the ages of 12 to 15 years in girls and 14 to 17 years in boys, adequate bone mass may not be achieved, and the risk of fracture could increase in pediatric-onset IBD patients. ${ }^{35,44}$ Furthermore, a significant proportion of pediatriconset CD patients suffer from growth retardation and undernutrition during the course of the disease ${ }^{19}$ In contrast, pediatric-onset UC patients may not show significant growth retardation after the initiation of medical therapy. ${ }^{45}$ With regard to pubertal maturity, pediatric-onset IBD patients showed a tendency toward delayed puberty. ${ }^{46,47}$ The median ages of menarche of girls with IBD and the general population were 14.6 and 13.1 years, respectively. ${ }^{47}$ The age of onset of puberty (testicular volume $>4 \mathrm{~mL}$ ) in boys with IBD and in the general population was 13.9 and 12.9 years, respectively. ${ }^{47}$

In summary, there is a difference in epidemiology and clinical characteristics between pediatric-onset and adult-onset IBD. Pediatric-onset IBD patients usually show more extensive bowel involvement and worse disease course compared to adult-onset IBD patients. Growth and pubertal maturity are significant issues in pediatric-onset IBD.

\section{DIAGNOSTIC TESTS AND TREATMENTS OF PEDIATRIC-ONSET AND ADULT-ONSET IBD}

Radiologic imaging modalities such as CT scans and MRI in the diagnosis and management of CD showed similar sensitivity and specificity for both pediatric-onset and adult-onset IBD patients. ${ }^{48}$ However, when performing radiologic imaging tests especially in pediatric patients, care providers should consider not only the diagnostic accuracy of the tests, but also the minimization of ionizing radiation exposures from CT and barium studies, the possibility of taking oral contrast agents, and the tolerability for a long time inside magnetic resonance scanncer. ${ }^{48,49}$ Furthermore, since suboptimal bowel preparation can occur in up to one-third of colonoscopies in pediatric patients, ideal preparation protocol to achieve optimal bowel preparation should be considered. ${ }^{50}$ Due to difficulties in performing radiologic and endoscopic evaluation in pediatric IBD patients, non-invasive diagnostic and monitoring tools such as fecal calprotectin could be more useful in pediatric patients.

Since exclusive enteral nutrition has an excellent safety profile and similar efficacy compared with corticosteroids in in- ducing remission, it is recommenced as a steroid-sparing treatment for the induction of remission in pediatric-onset CD patients with active luminal disease. ${ }^{51}$ In recent studies, $12 \%$ to $37 \%$ of pediatric-onset CD patients were reported to be corticosteroid-dependent, which is similar to the proportion of corticosteroid-dependent pediatric-onset UC patients (10\%$50 \%){ }^{19,36}$ The cumulative rates of requiring corticosteroids (96\% vs. $91 \%, P=0.03$ ), thiopurine ( $72 \%$ vs. $61 \%, P<0.01$ ), methotrexate $(19 \%$ vs. $10 \%, P<0.01)$, and anti-TNF agent $(26 \%$ vs. $13 \%, P<0.001)$ were significantly higher in pediatric-onset CD than in adult-onset CD according to a matched comparison study conducted in France. ${ }^{34}$ The use of immunomodulators has significantly increased over time, and this has been associated with a reduction in surgical risk in pediatric-onset CD patients. ${ }^{21,52}$ The rates of primary and long-term response to infliximab in pediatric-onset CD patients were reported as $75 \%$ to $97 \%$ and $54 \%$ to $83 \%$, respectively. ${ }^{19}$ The efficacy and safety profiles of infliximab seems to be similar to those of adult-onset CD patients. ${ }^{53}$ Although there were no significant differences in the cumulative risk of surgery, the risk of having an extensive intestinal resection ( $48 \% \pm 5 \%$ vs. $14 \% \pm 2 \%, P<0.001$ ) and permanent stoma ( $12 \% \pm 3 \%$ vs. $1 \% \pm 0.5 \%, P<0.001)$ were significantly higher in pediatric-onset $\mathrm{CD}$ than in adult-onset CD patients till the age of 30 years. ${ }^{34}$

Pediatric-onset UC patients often have extensive disease with aggressive phenotypes, and escalation to immunomodulators and anti-TNF agents is therefore indicated more frequently compared with adult-onset UC patients. ${ }^{54}$ In a populationbased cohort study from Copenhagen County and City, systemic corticosteroids and immunomodulators were more commonly used, and corticosteroid-dependency was more frequently observed in pediatric-onset UC patients than adultonset UC patients. ${ }^{55}$ From a meta-analysis of population-based studies, the pooled risk of colectomy at 1,5 , and 10 years after diagnosis was $7 \%, 17 \%$, and $22 \%$, respectively in pediatric-onset UC patients. ${ }^{56}$ Meanwhile, the pooled risk of colectomy was $5 \%, 12 \%$, and $16 \%$, respectively among all age groups of UC patients diagnosed after $1955 .{ }^{56}$ The risk of colectomy at 5 years was significantly higher in pediatric populations $(P=0.02) .^{56}$

Growth and pubertal maturity have a significant impact on decisions regarding treatment policy, particularly in children requiring optimal nutritional support, pharmacological treatment, and surgical treatment. ${ }^{54}$ Enteral nutrition helps to restore nutritional status, and anti-TNF agents can increase growth rate by inducing and maintaining remission in pediatric-onset CD patients. ${ }^{57}$ According to small cohort studies, infliximab 
has been reported to be helpful for restoring linear growth and weight gain as well as improving intestinal inflammation in pediatric CD patients, and clinical response to adalimumab has also been reported to be associated with linear growth. ${ }^{57-59}$ Moreover, improvement in linear growth after infliximab administration could be independent of the progression of puberty and reduction of glucocorticoid dose. ${ }^{60}$ Monitoring growth and pubertal development is important for assessing the impacts of the disease itself and the response to treatment, particularly in pediatric-onset CD patients. ${ }^{39}$

\section{WHAT IS THE TRANSITION OF CARE?}

Transfer of care refers to the actual movement of patients and their medical records from one healthcare provider to another at a specific point in time. ${ }^{3,14}$ In contrast, the transition of care is a process rather than a single point in time, which is defined as "the purposeful and planned movement that addresses the medical, psychosocial and educational/vocational needs of adolescents and young adults with chronic physical and medical conditions as they move from child-centered to adult-oriented healthcare systems." ${ }^{\text {"6-63 }}$ The optimal goal of the transition of care is to provide consistent, harmonious, developmentally appropriate, psychosocially sound, and comprehensive healthcare to patients with IBD. ${ }^{61}$

Successful transition can help normalize growth and development, promote independent behavior, improve compliance with therapy, provide an appropriate environment, and establish long-term plans. ${ }^{64}$ However, the failure of transition can lead to non-adherence to medical therapy, poor healthcare attendance, and the subsequent flare leading to deterioration of disease course, which is a major challenge for healthcare providers. ${ }^{65,66}$ Moreover, adolescence, the period when the transitioning process is usually initiated, is a crucial time of change in the lives of patients, when patterns of lifelong health behaviors are established. ${ }^{67}$

Transition encompasses both pediatric and adult care ${ }^{68} \mathrm{Pe}-$ diatric care differs from adult care in that it tends to be familycentered, and multidisciplinary practices therefore often require parental direction and consent. ${ }^{63}$ In contrast, adult care tends to be patient-centered and is mainly provided by a single doctor, and autonomous and independent patients are expected in an adult care setting. ${ }^{63}$ A transitioning patient may find it difficult to adapt to adult care, which focuses on cancer surveillance, sexual function, fertility, and pregnancy in contrast to the focus on growth and development in pediatric care. ${ }^{65}$

\section{TRANSITION PROCESS}

The transition process can be started most sensibly when the patient is capable of abstract thinking and future orientation. ${ }^{63}$ This usually begins in the early adolescence of patients-at the age of 10 to 12 years-and the final transfer to adult care occurs most often between 18 and 23 years of age.$^{14}$ However, this is a flexible rather than a rigid protocol that must be tailored to the patients' developmental abilities and situation. ${ }^{64}$ According to the position statements of the North American Society for Pediatric Gastroenterology, Hepatology and Nutrition published in 2002, pediatric care providers should initiate a transition process when the patients enters early to middle adolescence by meeting them without their parents, discussing the benefits of transition with the patient and family, developing relationships with competent adult care providers, and transferring all necessary medical information and summaries. ${ }^{64}$

Healthcare transition planning algorithms for children and youth with special healthcare needs were proposed in 2011 to assist healthcare providers in their execution of the transitional process and provide information about the transition structure for pediatric patients and their families. ${ }^{11}$ In this context, action steps developed according to a patient's specific age range are of particular importance. ${ }^{11}$ At 12 to 13 years of age, after the initiation of transition planning, a written transition policy that explicitly states the expectations associated with the care practices and processes should be shared with patients and their families. ${ }^{11}$ At 14 to 15 years of age, the patient's transition readiness is assessed, and a transition plan is jointly developed through patient and family interviews. ${ }^{11}$ Transition plans should be reviewed on a regular basis and updated as needed at 16 to 17 years of age. After preparing for adult care, the implementation of the adult care model occurs in patients aged 18 or over, who have already completed the previous steps. ${ }^{11}$

In general, the key competencies that should be gained during the transition process include knowledge about the medical condition and its treatment, self-efficacy, self-management, decision making, problem solving, self-advocacy, and information gathering. ${ }^{65}$ Self-management skills include medication adherence and the adequate management of symptoms, side effects of medication, stress, and emotion. ${ }^{69,70}$ However, in practice, a high proportion of adult and pediatric gastroenterologists reported inadequacies in the preparation of patients for transfer, and there was a significant difference in perceived inadequacies between adult and pediatric gastroenterologists 
( $79 \%$ vs. $42 \%, P=0.001$ ). ${ }^{9}$ The acquisition of knowledge and self-management skills should proceed with a stepwise approach, and tasks for the patient and medical team according to the patients' chronological age have been proposed in the form of a checklist (Fig. 1). ${ }^{63}$ Smartphone applications, such as GI buddy, myIBD+, and myColitis, can be helpful as tools to track the symptoms, diet, mood, and medication use of IBD patients and to improve their knowledge of IBD and self-management skills. ${ }^{71}$

Although there has been no universal instrument for measuring transition readiness, the Transition Readiness Assessment Questionnaire, the Social-ecological Model of Adolescents and Young Adults Readiness for Transition (SMART), the Readiness for Transition Questionnaire, and the University of North Carolina TRxANSITION scales were developed to evaluate the transition readiness for chronic health conditions. ${ }^{72-76}$ For IBD patients, MyHealth Passport and the checklist by Fishman et al. were also developed. ${ }^{77,78}$ In addition, the IBD Self-efficacy Scale for Adolescents and Young Adults (IBDSES-A) and a questionnaire (IBD-yourself) for evaluating self-efficacy have been introduced. ${ }^{79-81}$ Patients are considered eligible for adult care when most of the transition readiness skills have been mastered, the underlying disease is mild or quiescent, a patient has identified an adult care provider, and the pediatric care providers consider it likely that transition will be successful. ${ }^{13}$

Fig. 2. summarizes what we must consider and monitor during the different stages including before, just before, and during transition process. ${ }^{82}$

\begin{tabular}{|c|c|}
\hline Age & Patient \\
\hline $11-13$ & $\begin{array}{l}\square \text { Able to articulate his or her GI condition } \\
\square \text { Able to name medications, doses, side effects } \\
\square \text { Knows strategies to take his or her medication } \\
\square \text { Able to use and read a thermometer } \\
\square \text { Articulates impact of IBD on school and daily life }\end{array}$ \\
\hline $14-16$ & $\begin{array}{l}\square \text { Able to identify medical team } \\
\square \text { Knows names and purposes of procedures and tests done on } \\
\text { him or her } \\
\square \text { Knows his or her medical history } \\
\square \text { Knows names of IBD social support groups and community } \\
\text { organizations } \\
\square \text { Understands the medical risk of nonadherence } \\
\square \text { Understands the impact of drugs and alcohol on the illness }\end{array}$ \\
\hline
\end{tabular}

17-19 $\square$ Knows how to gather information about IBD

$\square$ Demonstrates consistent ability to book own appointments, fill prescriptions, contact medical team

$\square$ Able to name his or her insurance coverage and plans for next 2 years of coverage

$\square$ Carries insurance information in wallet/purse/backpack

20-23 $\square$ Has had a telephone conversation with potential adult GI providers

$\square$ Initial visit with adult GI provider is scheduled while IBD is stable $\square$ Directs all questions and explanations to patient

$\square$ Patient asked for input first

$\square$ Explores family's apprehension about patient taking on primary role

$\square$ Clarifies to patient what must legally be disclosed to parents

$\square$ Determines when the patient wants his or her parents in and out of the room

$\square$ Initiates discussion about eventual transfer of care

$\square$ Determines post high school plans (social, employment, education)

$\square$ Instructs patient how to access medical records

$\checkmark$ Instructs patient to keep names of medications/dosages and medical team in wallet/purse/backpack

$\square$ Instructs patient on how to get prescriptions filled and how to call and schedule appointments

Initiates conversation about potential barriers to transition

$\square$ Identifies potential adult GI providers

$\square$ Encourages patient to meet and interview providers

$\square$ Reminds patient and family that at age 18 years, the patient has the right to make his or her own health choices

$\square$ Provides patient with medical summary and checklist

$\square$ Transfers medical records to adult providers

Fig. 1. Checklists of transition readiness according to chronological age. Checklist of tasks for the patient and the medical team based on chronological age. Adapted from Hait E, et al. Inflamm Bowel Dis 2006;12:70-73, with permission from Oxford University Press. ${ }^{63}$ 


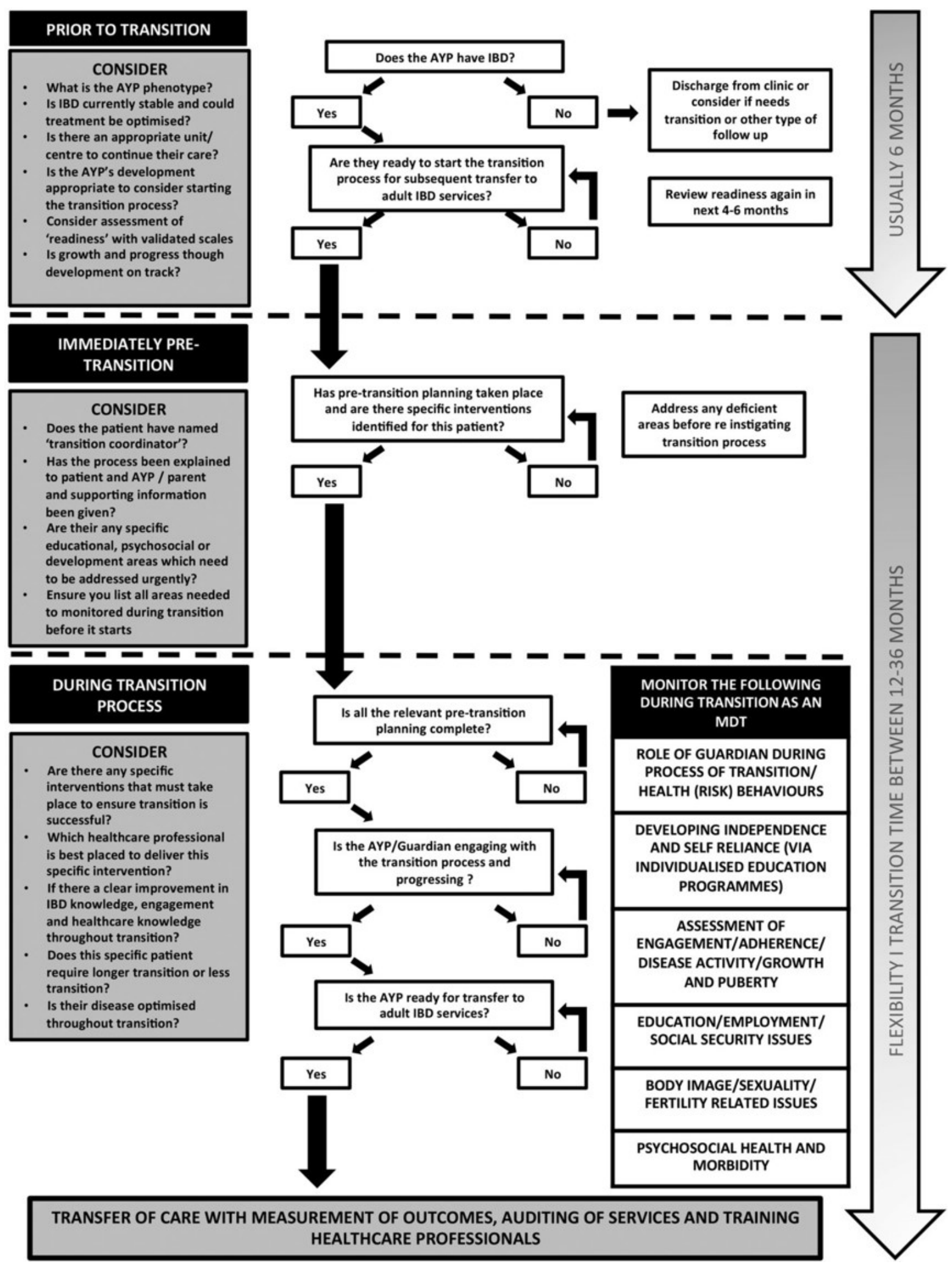

Fig. 2. What to consider and monitor in different stages of pediatric patients undergoing transition. A summary of the different stages of adolescents and young people (AYP) with IBD transition that highlights elements that must be monitored during this process from the perspective of pediatric to adult healthcare services. MDT, multidisciplinary team. Adapted from Brooks AJ, et al. Frontline Gastroenterol 2018;9:37-44, with permission from BMJ Publishing Group Ltd. ${ }^{82}$ 


\section{OBSTACLES TO SUCCESSFUL TRANSITION}

Previous studies have reported that pediatric-onset IBD patients demonstrated deficits in important knowledge regarding their medical history and medication regimens and deficits in their self-management skills. ${ }^{8,70}$ In a cross-sectional assessment of knowledge among Canadian patients, less than $50 \%$ of pediatric patients responded correctly to questions about small bowel X-ray results (9\%), their overall disease location (22\%), health service resources such as insurance providers (30\%) and pharmacy (35\%), their previous surgery (31\%), and the date, within 6 months, of their most recent colonoscopic evaluation (45\%). ${ }^{77}$ Compared with their parents, pediatric patients were less knowledgeable about the date of their last admission and health service resources, although other items were not significantly different between pediatric patients and their parents. ${ }^{77} \mathrm{~A}$ survey of adult gastroenterologists in the United States also reported that pediatric-onset IBD patients lacked knowledge of their medical history (55\%) and medication regimen (69\%), and moreover, $51 \%$ of doctors noted that they had received inadequate medical history from pediatric care providers. ${ }^{8}$ Therefore, tools that can be used as a portable medical record, such as the MyHealth Passport for IBD, can help reduce this knowledge gap. ${ }^{77}$

Self-management behaviors are influenced by sociodemographic factors, such as level of education and employment status; disease or disease regimen factors; individual factors; and family, social, and healthcare system factors. ${ }^{70}$ Approximately $38 \%$ to $66 \%$ of pediatric-onset IBD patients have shown medication non-adherence in previous reports, with variation depending on the respondents, the type of medication, and the method of evaluation. ${ }^{83-87}$ Pediatric-onset IBD patients responded that barriers to adherence were lack of time (33\%), feeling well (16\%), adverse drug reactions (14\%), the belief that the medication was not working (14\%), pharmacy barriers (8\%), and insurance barriers (5\%). ${ }^{83}$

According to a national survey of pediatric care providers in the United States, the most frequently mentioned barriers to successful transition were (in order of frequency) the reluctance of patients and parents, unpreparedness of patients, lack of resources/manpower, poor coordination of care between pediatric and adult care providers, the reluctance of the provider, and difficulty in finding an adult provider. ${ }^{12}$ The components of the SMART scale includes the following barriers to or facilitators of transition: preexisting objective factors; sociodemographic/culture, healthcare access/insurance, health sta- tus/risk, neurocognition/intelligent quotient, and interrelated subjective variables; knowledge, skills/efficacy, beliefs/expectations, goals, relationships, and psychosocial functioning. ${ }^{68,74}$ Those SMART components that addressed the patient's level of developmental maturity, the style of parental involvement, and the degree of support from providers were reported to influence transitional outcomes such as healthcare utilization, health status, and quality of life. ${ }^{88}$

According to a survey of adult and pediatric gastroenterologists in the United Kingdom, the main organizational obstacles include a lack of funding and support services; a lack of time, space, and training; and the small number of patients. ${ }^{9}$ The desired resources of United States pediatricians includes additional staff, reimbursement for transition-related services, and joint clinic visits with pediatric and adult providers. ${ }^{12}$

\section{OUTCOMES OF TRANSITION}

During the transition from pediatric to adult care, there is a high risk of non-adherence to treatment. If done poorly, transition can affect not only the use of health services but also the patient's health. ${ }^{89}$ Although there have been few studies on patients with IBD, implementing an effective transition care program can help improve patients' medication adherence and their health and life outcomes while promoting self-reliance. ${ }^{89,90}$

In a study of IBD patients who had been transitioned to adult care in France, most patients (85\%) stated that they felt ready for transition, and both patients and their parents' attend to a joint medical clinic with pediatric and adult gastroenterologists were considered beneficial for building patients' confidence in new providers and transmitting information. ${ }^{91}$ In a recent study conducted in Israel, pediatric-onset IBD patients attended a multidisciplinary transition clinic with a pediatric gastroenterologist, an adult gastroenterologist, an IBD nurse, a psychologist, and a nutritionist as needed, in 4 structured visits over a period of 6 months. ${ }^{80}$ The self-efficacy scores in all of the domains such as knowledge of IBD, treatment and transition process, self-efficacy in medication use, skills for independent outpatient clinic visits, actual behavior at the outpatient clinic, coping with IBD, and transfer readiness improved significantly after transition, and the level of improvement correlated to the number of meetings in the clinic. ${ }^{80}$

In a prospective study conducted in Canada, pediatric patients attending a transition clinic had stronger beliefs regarding the necessity for IBD drugs $(P=0.004)$, were less skeptical ( $7 \%$ vs. $21 \%, P=0.03$ ), and were more ambivalent ( $61 \%$ vs. $34 \%$, 
$P=0.004)$ in terms of their attitudes toward medicine than a control group, although self-reported adherence was not statistically different compared with controls. ${ }^{92}$ In a retrospective study conducted in the United Kingdom, patients who experienced a transition program showed a higher percentage of medication adherence ( $89 \%$ vs. $46 \%, P=0.002$ ), a lower surgical rate (25\% vs. $46 \%, P=0.01)$ or hospitalization rate (29\% vs. $61 \%, P=0.002$ ) within 2 years of transfer, and a lower rate of nonattendance at the clinic ( $29 \%$ vs. $78 \%, P=0.001)$ than those who did not. ${ }^{93}$ In this study, however, interpretation was limited because there were some differences in disease duration and medication history, although these were not significant. ${ }^{93}$

\section{CONCLUSIONS}

Pediatric-onset IBD patient in the transition period stand at the crossroads between being an independent adult who has acquired knowledge and self-management skills and remaining a dependent child. Transition encompasses both pediatric and adult care, and the care providers who are responsible for transition should understand the difference between pediatric-onset and adult-onset IBD. Furthermore, to ensure successful transition, healthcare providers must have a precise understanding of the transition process, its obstacles, and its outcomes and should share this understanding with the patients and their families or other care providers.

\section{FINANCIAL SUPPORT}

The authors received no financial support for the research, authorship, and/or publication of this article.

\section{CONFLICT OF INTEREST}

BDY has received a research grant from Celltrion; consulting fees from Abbvie Korea, Ferring Korea, Janssen Korea, Kangstem Biotech, Kuhnil Pharm., Shire Korea, Takeda Korea, IQVIA, Cornerstones Health, and Robarts Clinical Trials Inc.; speaking fees from Abbvie Korea, Janssen Korea, Shire Korea, Takeda Korea, and IQVIA. However, all of these are not relevant to this article.

\section{AUTHOR CONTRIBUTION}

Conceptualization, writing, editing, and approval of the final manuscript: Ye BD. Conceptualization and writing: Kim J.

\section{REFERENCES}

1. Benchimol EI, Fortinsky KJ, Gozdyra P, Van den Heuvel M, Van Limbergen J, Griffiths AM. Epidemiology of pediatric inflammatory bowel disease: a systematic review of international trends. Inflamm Bowel Dis 2011;17:423-439.

2. Benchimol EI, Mack DR, Nguyen GC, et al. Incidence, outcomes, and health services burden of very early onset inflammatory bowel disease. Gastroenterology 2014;147:803-813.

3. Afzali A, Katz S. Inflammatory bowel disease in the baby to baby boomer: pediatric and elderly onset of IBD. Curr Treat Options Gastroenterol 2018;16:289-305.

4. Sýkora J, Pomahačová R, Kreslová M, Cvalínová D, Štych P, Schwarz J. Current global trends in the incidence of pediatric-onset inflammatory bowel disease. World J Gastroenterol 2018; 24:2741-2763.

5. Paul T, Birnbaum A, Pal DK, et al. Distinct phenotype of early childhood inflammatory bowel disease. J Clin Gastroenterol 2006;40:583-586.

6. Van Limbergen J, Russell RK, Drummond HE, et al. Definition of phenotypic characteristics of childhood-onset inflammatory bowel disease. Gastroenterology 2008;135:1114-1122.

7. Goodhand J, Hedin CR, Croft NM, Lindsay JO. Adolescents with IBD: the importance of structured transition care. J Crohns Colitis 2011;5:509-519.

8. Hait EJ, Barendse RM, Arnold JH, et al. Transition of adolescents with inflammatory bowel disease from pediatric to adult care: a survey of adult gastroenterologists. J Pediatr Gastroenterol Nutr 2009;48:61-65.

9. Sebastian S, Jenkins H, McCartney S, et al. The requirements and barriers to successful transition of adolescents with inflammatory bowel disease: differing perceptions from a survey of adult and paediatric gastroenterologists. J Crohns Colitis 2012;6:830-844.

10. American Academy of Pediatrics; American Academy of Family Physicians; American College of Physicians-American Society of Internal Medicine. A consensus statement on health care transitions for young adults with special health care needs. Pediatrics 2002;110:1304-1306.

11. American Academy of Pediatrics; American Academy of Family Physicians; American College of Physicians; Transitions Clinical Report Authoring Group, Cooley WC, Sagerman PJ. Supporting the health care transition from adolescence to adulthood in the medical home. Pediatrics 2011;128:182-200.

12. Gray WN, Maddux MH. Current transition practices in pediatric IBD: findings from a national survey of pediatric provid- 
ers. Inflamm Bowel Dis 2016;22:372-379.

13. Gray WN, Holbrook E, Morgan PJ, Saeed SA, Denson LA, Hommel KA. Transition readiness skills acquisition in adolescents and young adults with inflammatory bowel disease: findings from integrating assessment into clinical practice. Inflamm Bowel Dis 2015;21:1125-1131.

14. Zeisler B, Hyams JS. Transition of management in adolescents with IBD. Nat Rev Gastroenterol Hepatol 2014;11:109-115.

15. Clarke T, Lusher J. Transitioning patients with inflammatory bowel disease (IBD) from adolescent to adult services: a systematic review. Frontline Gastroenterol 2016;7:264-270.

16. Afzali A, Wahbeh G. Transition of pediatric to adult care in inflammatory bowel disease: is it as easy as 1, 2, 3? World J Gastroenterol 2017;23:3624-3631.

17. van Rheenen PF, Aloi M, Biron IA, et al. European Crohn's and Colitis Organisation topical review on transitional care in inflammatory bowel disease. J Crohns Colitis 2017;11:1032-1038.

18. Philpott JR, Kurowski JA. Challenges in transitional care in inflammatory bowel disease: a review of the current literature in transition readiness and outcomes. Inflamm Bowel Dis 2019;25:45-55.

19. Duricova D, Fumery M, Annese V, Lakatos PL, Peyrin-Biroulet L, Gower-Rousseau C. The natural history of Crohn's disease in children: a review of population-based studies. Eur J Gastroenterol Hepatol 2017;29:125-134.

20. Heyman MB, Kirschner BS, Gold BD, et al. Children with early-onset inflammatory bowel disease (IBD): analysis of a pediatric IBD consortium registry. J Pediatr 2005;146:35-40.

21. Vernier-Massouille G, Balde M, Salleron J, et al. Natural history of pediatric Crohn's disease: a population-based cohort study. Gastroenterology 2008;135:1106-1113.

22. Kappelman MD, Rifas-Shiman SL, Kleinman K, et al. The prevalence and geographic distribution of Crohn's disease and ulcerative colitis in the United States. Clin Gastroenterol Hepatol 2007;5:1424-1429.

23. Ishige T, Tomomasa T, Takebayashi T, et al. Inflammatory bowel disease in children: epidemiological analysis of the nationwide IBD registry in Japan. J Gastroenterol 2010;45:911-917.

24. Cosnes J, Gower-Rousseau C, Seksik P, Cortot A. Epidemiology and natural history of inflammatory bowel diseases. Gastroenterology 2011;140:1785-1794.

25. Bernstein CN, Wajda A, Svenson LW, et al. The epidemiology of inflammatory bowel disease in Canada: a population-based study. Am J Gastroenterol 2006;101:1559-1568.

26. Oh SH, Kim KM. Current issues of pediatric inflammatory bowel disease in Korea. Korean J Pediatr 2014;57:465-471.
27. Adamiak T, Walkiewicz-Jedrzejczak D, Fish D, et al. Incidence, clinical characteristics, and natural history of pediatric IBD in Wisconsin: a population-based epidemiological study. Inflamm Bowel Dis 2013;19:1218-1223.

28. Charpentier C, Salleron J, Savoye G, et al. Natural history of elderly-onset inflammatory bowel disease: a population-based cohort study. Gut 2014;63:423-432.

29. de Bie CI, Paerregaard A, Kolacek S, et al. Disease phenotype at diagnosis in pediatric Crohn's disease: 5-year analyses of the EUROKIDS Registry. Inflamm Bowel Dis 2013;19:378-385.

30. Levine A, de Bie CI, Turner D, et al. Atypical disease phenotypes in pediatric ulcerative colitis: 5-year analyses of the EUROKIDS Registry. Inflamm Bowel Dis 2013;19:370-377.

31. Hong SJ, Cho SM, Choe BH, et al. Characteristics and incidence trends for pediatric inflammatory bowel disease in Daegu-Kyungpook Province in Korea: a multi-center study. J Korean Med Sci 2018;33:e132.

32. Kim HJ, Oh SH, Kim DY, et al. Clinical characteristics and longterm outcomes of paediatric Crohn's disease: a single-centre experience. J Crohns Colitis 2017;11:157-164.

33. Wang XQ, Xiao Y, Xu X, et al. Study of disease phenotype and its association with prognosis of paediatric inflammatory bowel disease in China. BMC Pediatr 2018;18:229.

34. Pigneur B, Seksik P, Viola S, et al. Natural history of Crohn's disease: comparison between childhood- and adult-onset disease. Inflamm Bowel Dis 2010;16:953-961.

35. Nasiri S, Kuenzig ME, Benchimol EI. Long-term outcomes of pediatric inflammatory bowel disease. Semin Pediatr Surg 2017;26:398-404.

36. Fumery M, Duricova D, Gower-Rousseau C, Annese V, Peyrin-Biroulet L, Lakatos PL. Review article: the natural history of paediatric-onset ulcerative colitis in population-based studies. Aliment Pharmacol Ther 2016;43:346-355.

37. Griffiths AM. Specificities of inflammatory bowel disease in childhood. Best Pract Res Clin Gastroenterol 2004;18:509-523.

38. Vaisman N, Dotan I, Halack A, Niv E. Malabsorption is a major contributor to underweight in Crohn's disease patients in remission. Nutrition 2006;22:855-859.

39. Gasparetto M, Guariso G. Crohn's disease and growth deficiency in children and adolescents. World J Gastroenterol 2014; 20:13219-13233.

40. Rosen MJ, Dhawan A, Saeed SA. Inflammatory bowel disease in children and adolescents. JAMA Pediatr 2015;169:1053-1060.

41. Heuschkel R, Salvestrini C, Beattie RM, Hildebrand H, Walters T, Griffiths A. Guidelines for the management of growth failure in childhood inflammatory bowel disease. Inflamm Bowel 
Dis 2008;14:839-849.

42. Ley D, Duhamel A, Behal H, et al. Growth pattern in paediatric Crohn disease is related to inflammatory status. J Pediatr Gastroenterol Nutr 2016;63:637-643.

43. Lee JJ, Escher JC, Shuman MJ, et al. Final adult height of children with inflammatory bowel disease is predicted by parental height and patient minimum height Z-score. Inflamm Bowel Dis 2010;16:1669-1677.

44. Davies JH, Evans BA, Gregory JW. Bone mass acquisition in healthy children. Arch Dis Child 2005;90:373-378.

45. Jakobsen C, Paerregaard A, Munkholm P, et al. Pediatric inflammatory bowel disease: increasing incidence, decreasing surgery rate, and compromised nutritional status: a prospective population-based cohort study 2007-2009. Inflamm Bowel Dis 2011;17: 2541-2550.

46. Ballinger AB, Savage MO, Sanderson IR. Delayed puberty associated with inflammatory bowel disease. Pediatr Res 2003; 53:205-210.

47. Perminow G, Brackmann S, Lyckander LG, et al. A characterization in childhood inflammatory bowel disease, a new population-based inception cohort from South-Eastern Norway, 2005-07, showing increased incidence in Crohn's disease. Scand J Gastroenterol 2009;44:446-456.

48. Duigenan S, Gee MS. Imaging of pediatric patients with inflammatory bowel disease. AJR Am J Roentgenol 2012;199: 907-915

49. Towbin AJ, Sullivan J, Denson LA, Wallihan DB, Podberesky DJ. CT and MR enterography in children and adolescents with inflammatory bowel disease. Radiographics 2013;33:18431860.

50. Pall H, Zacur GM, Kramer RE, et al. Bowel preparation for pediatric colonoscopy: report of the NASPGHAN endoscopy and procedures committee. J Pediatr Gastroenterol Nutr 2014;59: 409-416.

51. Ruemmele FM, Veres G, Kolho KL, et al. Consensus guidelines of ECCO/ESPGHAN on the medical management of pediatric Crohn's disease. J Crohns Colitis 2014;8:1179-1207.

52. Lakatos PL, Golovics PA, David G, et al. Has there been a change in the natural history of Crohn's disease? Surgical rates and medical management in a population-based inception cohort from Western Hungary between 1977-2009. Am J Gastroenterol 2012;107:579-588.

53. Vilar P, de Carpi JM, Acuña CE, Masiques MA. Infliximab in paediatric inflammatory bowel disease. J Crohns Colitis 2007; $1: 2-9$.

54. Ruemmele FM, Turner D. Differences in the management of pediatric and adult onset ulcerative colitis: lessons from the joint ECCO and ESPGHAN consensus guidelines for the management of pediatric ulcerative colitis. J Crohns Colitis 2014;8: $1-4$

55. Jakobsen C, Bartek J Jr, Wewer V, et al. Differences in phenotype and disease course in adult and paediatric inflammatory bowel disease: a population-based study. Aliment Pharmacol Ther 2011;34:1217-1224.

56. Frolkis AD, Dykeman J, Negrón ME, et al. Risk of surgery for inflammatory bowel diseases has decreased over time: a systematic review and meta-analysis of population-based studies. Gastroenterology 2013;145:996-1006.

57. Malik S, Ahmed SF, Wilson ML, et al. The effects of anti-TNFalpha treatment with adalimumab on growth in children with Crohn's disease (CD). J Crohns Colitis 2012;6:337-344.

58. Borrelli O, Bascietto C, Viola F, et al. Infliximab heals intestinal inflammatory lesions and restores growth in children with Crohn's disease. Dig Liver Dis 2004;36:342-347.

59. Walters TD, Gilman AR, Griffiths AM. Linear growth improves during infliximab therapy in children with chronically active severe Crohn's disease. Inflamm Bowel Dis 2007;13:424-430.

60. Malik S, Wong SC, Bishop J, et al. Improvement in growth of children with Crohn disease following anti-TNF-alpha therapy can be independent of pubertal progress and glucocorticoid reduction. J Pediatr Gastroenterol Nutr 2011;52:31-37.

61. Blum RW, Garell D, Hodgman CH, et al. Transition from childcentered to adult health-care systems for adolescents with chronic conditions: a position paper of the Society for Adolescent Medicine. J Adolesc Health 1993;14:570-576.

62. Gumidyala AP, Greenley RN, Plevinsky JM, et al. Moving on: transition readiness in adolescents and young adults with IBD. Inflamm Bowel Dis 2018;24:482-489.

63. Hait E, Arnold JH, Fishman LN. Educate, communicate, anticipate-practical recommendations for transitioning adolescents with IBD to adult health care. Inflamm Bowel Dis 2006;12:7073.

64. Baldassano R, Ferry G, Griffiths A, Mack D, Markowitz J, Winter $\mathrm{H}$. Transition of the patient with inflammatory bowel disease from pediatric to adult care: recommendations of the North American Society for Pediatric Gastroenterology, Hepatology and Nutrition. J Pediatr Gastroenterol Nutr 2002;34: 245-248.

65. de Silva PS, Fishman LN. Transition of the patient with IBD from pediatric to adult care-an assessment of current evidence. Inflamm Bowel Dis 2014;20:1458-1464.

66. Campbell F, Biggs K, Aldiss SK, et al. Transition of care for ad- 
olescents from paediatric services to adult health services. Cochrane Database Syst Rev 2016;4:CD009794.

67. Sawyer SM, Afifi RA, Bearinger LH, et al. Adolescence: a foundation for future health. Lancet 2012;379:1630-1640.

68. Gray WN, Schaefer MR, Resmini-Rawlinson A, Wagoner ST. Barriers to transition from pediatric to adult care: a systematic review. J Pediatr Psychol 2018;43:488-502.

69. Keefer L, Kiebles JL, Taft TH. The role of self-efficacy in inflammatory bowel disease management: preliminary validation of a disease-specific measure. Inflamm Bowel Dis 2011;17: 614-620.

70. Hommel KA, Greenley RN, Maddux MH, Gray WN, Mackner LM. Self-management in pediatric inflammatory bowel disease: a clinical report of the North American Society for Pediatric Gastroenterology, Hepatology, and Nutrition. J Pediatr Gastroenterol Nutr 2013;57:250-257.

71. Kahn SA. the transition from pediatric to adult inflammatory bowel disease care. Gastroenterol Hepatol (N Y) 2016;12:403406.

72. Sawicki GS, Lukens-Bull K, Yin X, et al. Measuring the transition readiness of youth with special healthcare needs: validation of the TRAQ: Transition Readiness Assessment Questionnaire. J Pediatr Psychol 2011;36:160-171.

73. Wood DL, Sawicki GS, Miller MD, et al. The Transition Readiness Assessment Questionnaire (TRAQ): its factor structure, reliability, and validity. Acad Pediatr 2014;14:415-422.

74. Schwartz LA, Tuchman LK, Hobbie WL, Ginsberg JP. A socialecological model of readiness for transition to adult-oriented care for adolescents and young adults with chronic health conditions. Child Care Health Dev 2011;37:883-895.

75. Gilleland J, Amaral S, Mee L, Blount R. Getting ready to leave: transition readiness in adolescent kidney transplant recipients. J Pediatr Psychol 2012;37:85-96.

76. Ferris ME, Harward DH, Bickford K, et al. A clinical tool to measure the components of health-care transition from pediatric care to adult care: the UNC TR(x)ANSITION scale. Ren Fail 2012;34:744-753.

77. Benchimol EI, Walters TD, Kaufman M, et al. Assessment of knowledge in adolescents with inflammatory bowel disease using a novel transition tool. Inflamm Bowel Dis 2011;17:11311137.

78. Fishman LN, Houtman D, van Groningen J, Arnold J, Ziniel S. Medication knowledge: an initial step in self-management for youth with inflammatory bowel disease. J Pediatr Gastroenterol Nutr 2011;53:641-645.

79. Izaguirre MR, Keefer L. Development of a self-efficacy scale for adolescents and young adults with inflammatory bowel disease. J Pediatr Gastroenterol Nutr 2014;59:29-32.

80. Yerushalmy-Feler A, Ron Y, Barnea E, et al. Adolescent transition clinic in inflammatory bowel disease: quantitative assessment of self-efficacy skills. Eur J Gastroenterol Hepatol 2017; 29:831-837.

81. Izaguirre MR, Taft T, Keefer L. Validation of a self-efficacy scale for adolescents and young adults with inflammatory bowel disease. J Pediatr Gastroenterol Nutr 2017;65:546-550.

82. Brooks AJ, Smith PJ, Lindsay JO. Monitoring adolescents and young people with inflammatory bowel disease during transition to adult healthcare. Frontline Gastroenterol 2018;9:37-44.

83. Greenley RN, Stephens M, Doughty A, Raboin T, Kugathasan S. Barriers to adherence among adolescents with inflammatory bowel disease. Inflamm Bowel Dis 2010;16:36-41.

84. Hommel KA, Davis CM, Baldassano RN. Objective versus subjective assessment of oral medication adherence in pediatric inflammatory bowel disease. Inflamm Bowel Dis 2009; 15:589-593.

85. Hommel KA, Davis CM, Baldassano RN. Medication adherence and quality of life in pediatric inflammatory bowel disease. J Pediatr Psychol 2008;33:867-874.

86. Mackner LM, Crandall WV. Oral medication adherence in pediatric inflammatory bowel disease. Inflamm Bowel Dis 2005; 11:1006-1012.

87. Oliva-Hemker MM, Abadom V, Cuffari C, Thompson RE. Nonadherence with thiopurine immunomodulator and mesalamine medications in children with Crohn disease. J Pediatr Gastroenterol Nutr 2007;44:180-184.

88. Paine CW, Stollon NB, Lucas MS, et al. Barriers and facilitators to successful transition from pediatric to adult inflammatory bowel disease care from the perspectives of providers. Inflamm Bowel Dis 2014;20:2083-2091.

89. Bennett AL, Moore D, Bampton PA, Bryant RV, Andrews JM. Outcomes and patients' perspectives of transition from paediatric to adult care in inflammatory bowel disease. World J Gastroenterol 2016;22:2611-2620.

90. Jeganathan J, Lee CH, Rahme A, et al. Pediatric-to-adult transition and medication adherence in patients with inflammatory bowel disease. Inflamm Bowel Dis 2017;23:1065-1070.

91. Dabadie A, Troadec F, Heresbach D, Siproudhis L, Pagenault $\mathrm{M}$, Bretagne JF. Transition of patients with inflammatory bowel disease from pediatric to adult care. Gastroenterol Clin Biol 2008;32:451-459.

92. Fu N, Jacobson K, Round A, Evans K, Qian H, Bressler B. Transition clinic attendance is associated with improved beliefs 
and attitudes toward medicine in patients with inflammatory bowel disease. World J Gastroenterol 2017;23:5405-5411.

93. Cole R, Ashok D, Razack A, Azaz A, Sebastian S. Evaluation of outcomes in adolescent inflammatory bowel disease patients following transfer from pediatric to adult health care services: case for transition. J Adolesc Health 2015;57:212-217. 